\title{
Theoretical aspects of human capital influence on regional development
}

\author{
$T$. Kokuytseva ${ }^{1}$ and $O$. Ovchinnikova ${ }^{1, *}$ \\ ${ }^{1}$ Peoples' Friendship University of Russia (RUDN University), Department of Applied Economics, \\ 117198, Miklukho-Maklaya str.6, Moscow, Russia
}

\begin{abstract}
This article is to discuss the state of scholarly research on the influence of human capital on the economic growth and the development of regions. We hereby review the relevant literature published over the past 30 years, and we integrate the various trends and factors into a preliminary and multi-dimensional framework of human capital development. Through this methodologically systematic review and framework development, we provide a more comprehensive and deeper understanding of the connection between human capital development, world technological trends and economic growth. In so doing, we consequently identify various research gaps and prescribe effective ways for future works in this research stream. Conclusively, we discuss the problem of a lack of the demand for human capital (as well as knowledge) in Russian regions that is the main reason for weak economic situation in them. Here is suggested to restructure current regional economy in order to consolidate high qualified human capital in regions and stipulate economic growth in regions.
\end{abstract}

\section{Introduction}

The development of human capital is currently becoming particularly relevant in Russia in connection with the need to ensure a qualitative technological breakthrough in the development of the country as a whole. "The point of our entire policy is to save people. Multiplication of human capital as the main wealth of Russia" (Russian President V. Putin).

In conditions of high speed of changes, global instability, as well as complicating international processes, the need for effective use of human capital to ensure the economic development of both the country as a whole and the regions in increasing way. However, regions cannot always evaluate the available human capital and ensure its effective use. Moreover, far from everytime the regional authorities and regional business are sufficiently aware of the need for a structure of human capital, namely, what human skills and competencies can ensure the economic growth of the territory.

Often, employers cannot find a suitable specialist in the market, so they hire people who do not have the necessary competence and invest in their retraining. In turn, the state allocates financial resources for the training of specialists whose skills and competencies do not meet the requirements of the market. Educational organizations train personnel to meet the current needs of the economy, which can change dramatically by the time a student

\footnotetext{
${ }^{*}$ Corresponding author: ovchinnikova-op@,rudn.ru
} 
graduates. Employers, in turn, are not sufficiently aware of what competencies an employee will need in four to six years. There is a personnel gap that does not contribute to the accumulation and effective use of human capital.

The main hypothesis of this study follows from the assertion that the accumulation of human capital and the need for it currently exist simultaneously at the regional level. The structure of the regional economy is such that it does not require significant participation of human capital. However, the state is actively stimulating an increase in the share of human capital in the structure of the economy.

As a result, it becomes necessary to study the process of the influence of human capital on the economic development of the territory and its theoretical justification.

\section{Literature review}

Many works of Russian and foreign scientists are devoted to the problems of the development of human capital and its impact on economic growth. Even in the works of W. Petty, "the monetary value of the population" was noted, although human capital itself was not yet considered an economic resource [1]. In the early 1990s in [2; 3], the effect was investigated human capital on economic growth rates, which allowed the authors to draw conclusions about the positive impact of investment in human capital.

With the beginning of the new millennium, there is a change in the assessment of the quality of human capital towards the inclusion of education, skills, qualifications and expert knowledge of people in the number of traditional forms of capital [4]. Specialists [5] believe that everything in the labor markets and skills of three types are becoming more important: developed cognitive skills (e.g., integrated problem solving), social and behavioral skills (e.g. teamwork), and a combination of skills that predetermine adaptability (e.g., logical thinking and self-confidence).

However, in the structure of human capital, most researchers emphasize the importance of the educational component. HSE Scientists in their studies showed the role of regions in the development of the educational infrastructure of the territory.

In the studies of foreign scientists, on the one hand, there is no direct relationship between human capital and economic growth $[3 ; 6]$.

On the other hand, a number of domestic and foreign scientists note the relationship between the level of development of human capital and economic growth $[7 ; 8]$.

A number of works by foreign and Russian scientists note the positive impact of human capital on the development and diffusion of technologies [9;10]. At the same time, a study conducted by scientists from the Institute for Socio-Economic Development of Territories of the Russian Academy of Sciences showed the ambiguity of such an effect[11].

\section{Theoretical research framework}

Technological changes that are characteristic of the 21 st century are rapidly changing the structure of production, making new demands on the quality of human capital. If, within the framework of the fourth and even fifth technological mode, a person needed a certain set of knowledge and skills that could provide him with a certain degree of development a workplace throughout his life, now the knowledge gained is quickly becoming obsolete. There was even a special term - "half-life of competencies", which refers to the period after graduation (it doesn't matter if it is a college, university or advanced training program), during which the acquired knowledge is outdated by $50 \%$. According to experts, the "halflife" of university knowledge is currently 2-4 years. From here a new model of education arises, suggesting step-by-step education, the time period of which is 2 years (model $2+2$ 
+2 ), and the key skill of a modern person is the ability to constantly learn and adapt to environmental uncertainties.

Table 1. Indicators characterizing the economic development of the territory and the quality of human capital (Central Federal District, data as of January 1, 2018) [12].

\begin{tabular}{|c|c|c|c|c|c|c|c|c|}
\hline 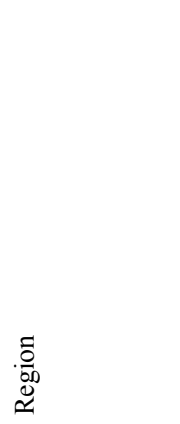 & 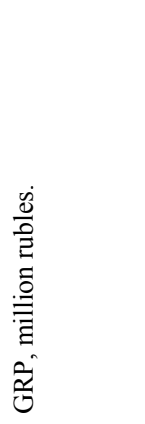 & 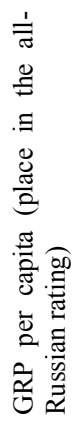 & 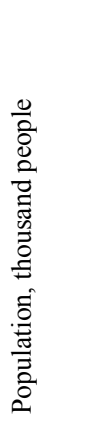 & 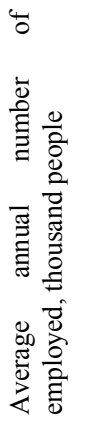 & 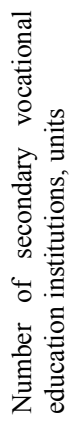 & 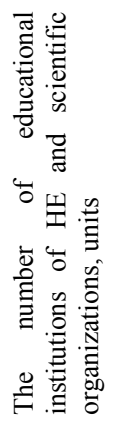 & 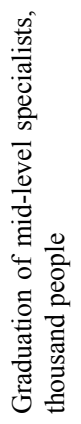 & 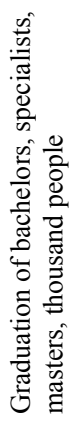 \\
\hline \multicolumn{9}{|c|}{ Central Federal District } \\
\hline $\begin{array}{l}\text { Belgorod } \\
\text { region }\end{array}$ & 730562,0 & 19 & 1550 & 757,9 & 37 & 5 & 5,1 & 11,3 \\
\hline $\begin{array}{l}\text { Bryansk } \\
\text { region }\end{array}$ & 285847,9 & 65 & 1211 & 530,2 & 27 & 5 & 4,5 & 6,0 \\
\hline $\begin{array}{l}\text { Vladimir } \\
\text { region }\end{array}$ & 392051,8 & 55 & 1378 & 640,6 & 42 & 3 & 4,4 & 6,1 \\
\hline $\begin{array}{l}\text { Voronezh } \\
\text { region }\end{array}$ & 841375,7 & 38 & 2333 & 1102,1 & 43 & 15 & 8,3 & 20,2 \\
\hline $\begin{array}{l}\text { Ivanovo } \\
\text { region }\end{array}$ & 179633,4 & 78 & 1015 & 456,3 & 38 & 6 & 3,1 & 6,7 \\
\hline Kaluga region & 373403,5 & 35 & 1012 & 504,8 & 29 & 3 & 3,1 & 3,6 \\
\hline $\begin{array}{l}\text { Kostroma } \\
\text { region }\end{array}$ & 160705,4 & 61 & 643 & 290,8 & 29 & 2 & 2,2 & 2,5 \\
\hline Kursk region & 364601,7 & 46 & 1115 & 519,6 & 30 & 8 & 4,7 & 8,9 \\
\hline Lipetsk region & 470239,3 & 25 & 1150 & 585,8 & 34 & 5 & 4,1 & 4,7 \\
\hline $\begin{array}{l}\text { Moscow } \\
\text { region }\end{array}$ & 3565258,0 & 17 & 7503 & 3450,2 & 77 & 24 & 16,2 & 16,0 \\
\hline Oryol Region & 213924,0 & 54 & 747 & 321,1 & 22 & 4 & 2,8 & 6,7 \\
\hline Ryazan Oblast & 336973,5 & 50 & 1122 & 511,0 & 36 & 6 & 4,7 & 6,9 \\
\hline $\begin{array}{l}\text { Smolensk } \\
\text { region }\end{array}$ & 262318,0 & 57 & 950 & 445,9 & 32 & 7 & 3,3 & 5,3 \\
\hline $\begin{array}{l}\text { Tambov } \\
\text { Region }\end{array}$ & 311433,4 & 51 & 1033 & 482,4 & 29 & 4 & 4,1 & 5,9 \\
\hline Tver region & 359345,1 & 56 & 1284 & 610,0 & 52 & 7 & 4,4 & 6,1 \\
\hline Tula region & 517740,8 & 42 & 1492 & 719,9 & 38 & 6 & 4,6 & 7,0 \\
\hline $\begin{array}{l}\text { Yaroslavl } \\
\text { region }\end{array}$ & 469804,9 & 34 & 1286 & 621,1 & 51 & 9 & 4,7 & 6,4 \\
\hline Moscow city & 14299800,6 & 6 & 12507 & 8730,0 & 100 & 161 & 31,0 & 200,2 \\
\hline
\end{tabular}

Obviously, the forecasting period in frames in similar conditions also has a short-term horizon. It was stated above that at present there is no clear position of scientists on the issue of the impact of human capital on economic growth. Let us consider some indicators characterizing the level of economic development of the territory (GRP, GRP per capita, population) and the quality of the territory's human capital according to the "education" parameter (number of VET organizations and HE organizations, graduation of middle managers and graduation of bachelors, specialists, masters). As a hypothesis, we assume that all specialists who graduated from educational institutions in the region form the basis of the human capital of the territory and for the most part remain working in the region. 
The data presented in the table are considered in the context of one federal district and in the time section - one year. The data show that in all the regions examined, a significant number of specialists with higher education are graduated annually, the number of midlevel specialists as a percentage is insignificant.

In addition, given that the knowledge possessed by graduates of educational organizations largely does not meet the requirements of the technological development of the territory, the region cannot count on a serious accumulation of human capital.

The data in the table show that, in general, the training system and the economy of the territory exist in parallel. Training is carried out to a greater extent as a temporary employment of young people who subsequently independently find a job and not always according to the qualifications received at the educational institution. Young people who cannot find work that matches their ambitions are trying to leave the region for capital cities and million-plus cities, where due to the greater concentration of resources there is a higher demand for human capital. Thus, human capital as a whole is poorly demanded by the regional economy.

As one of the barriers to the development of human capital at the regional level, BCG specialists called insignificant demand for highly qualified personnel. This is primarily due to the structure of the economy, where there are not enough jobs for highly qualified and, accordingly, expensive, "knowledgeable" personnel. More than $35 \%$ of employees relate mainly to low-skilled personnel with a certain basic set of "skills" necessary to perform certain routine work. At the same time, the absence of "knowledgeable" employees is a serious barrier to the development of territories in general.

Due to the lack of demand for highly educated and technologically advanced personnel, the training system (both at the middle level and at the higher education level) does not strive to form a modern training model. Despite the fact that the state is making significant efforts to create a modern model of education, in universities and colleges teachers are not ready to restructure the educational process due to the inertia of the educational system itself and the lack of explicit demand from employers for highly educated ("knowledgeable") personnel. In the educational environment, organizational resistance arises, which leads to a gap in technological (from the position of relevance to the requirements of technological development) training of students and teachers.

For a significant period in the recent history of Russia (beginning in the 1990s), the higher education system was regarded as a social norm. And if in the early 1990s the increase in the number of universities as some kind of "social safes" was justified from the perspective of youth employment due to lack of jobs, then starting from the second half of the "tenths" of this century it became clear that such a system is a brake on development economics.

Another problem is the lack of dialogue between employers and educational organizations. If you do not take into account the formal interaction, which is often expressed in the invitation of the employer to the examination committee, etc., then we can note the lack of interest on both sides to find mutually beneficial solutions. Result enterprises complain about the lack of trained personnel, and universities do not understand how the educational process should be conducted so that students are in demand in the market. In addition, there are no effective scalable practices of public-private partnerships, as well as systematic career guidance and training for the requirements of the employer.

When considering the development of human capital, one should also take into account global trends that can be distinguished at present.

1. Geopolitical trends. It is obvious that the globalized world economic system is currently undergoing significant changes. With a certain degree of probability, one can single out the emerging course of most countries towards the regionalization of the main processes. 
An example is the developing alliances of countries (BRICS, EU, EAEU, ASEAN, etc.), within which the countries agree on cooperation in key areas, including considering the problems of providing personnel, as well as the open exit of individual countries from existing Alliances (Brexit).

In addition, unpredictable events - the "black swans", such as the epidemic of the coronavirus COVID-19, may be a trigger for changing the economic and even political map of the world.

2. Demographic trends. The most famous trends include a significant increase in the world's population, including due to increased life expectancy, as well as an aging population in developed and developing countries.

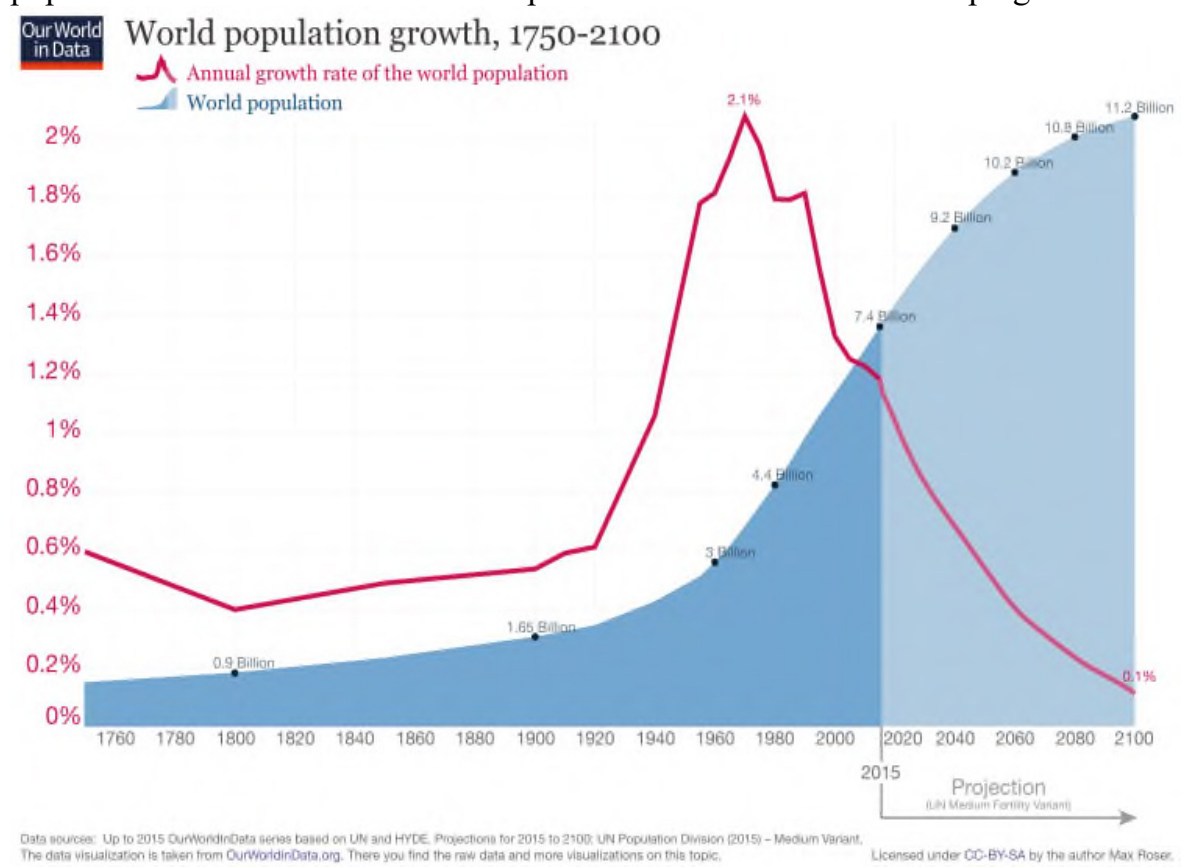

Fig. 1. Interdependence between population and growth rates. Source: Our World in Data.

Figure 1 shows the relationship between the number of people and their growth rates, which confirms the thesis that the number of the Earth's population is increasing, and the growth rate is falling.

3. In addition, another significant trend should be noted - generational change. Never in the history of mankind have there been such a difference in values, attitudes towards life, work, etc. in individuals of various generations. The people who are now forming the economic map of the world belong to three generations, which are conditionally defined as X (born 1963-1980), Y (1980-1995) and Z (1995-2010). By 2025, Generation Z will account for $25 \%$ of the total workforce.

In addition, people born after 2010 belong to the latest generation of Alpha, and their value orientations will be directly related to technological progress and to blurring the boundaries between the virtual and the real world.

4. Technological trends. Technological progress has a significant impact on the development of human capital and the structure of the labor market. It made the information as accessible as possible, which led to the denial of a long training period. And if earlier the process of finding the necessary information took months and years, then at present such a problem is not worth it, because any information can be found on the global 
Internet. Another problem arises: it is difficult for a person to understand the informational "noise" and to isolate really important and relevant information.

Demand creates supply. On the global information space there is a significant number of people who give out personal experience or individual information as sacred knowledge and share it with a wide audience. As a result, there is an informational bias - people believe in "opinion leaders" and do not want to seek information confirming or refuting their opinion, that is, the criticality of thinking is erased.

Technological trends affect the structure of the labor market. New forms of employment are emerging: freelance and remote employment, as well as self-employment, which became possible due to the wide development of platform solutions. A labor market arises within the framework of a "shared economy," requiring people to have completely new skills, such as self-organization skills.

The use of big data and algorithmic solutions entails a "polarization of qualifications", when the reduction will affect mainly low-skilled labor, which is cheap for the employer, but "average" personnel (administrative staff, accountants, lawyers, etc.). In other words, regulated labor can replace an algorithm that, for example, allows dynamic pricing to be cheaper than an employee. At the same time, production robotics will cost the employer more than the use of low-skilled labor. Personnel with a large amount of unique knowledge and competencies (for example, a well-known lawyer, crisis manager, etc.) are quite expensive and there is only one demand for it for employers.

However, technology, changing the labor market, is changing the structure of employment, which will complicate all professions. Automation will affect all professions, as even in the most creative profession there are simple, routine operations, which will free up time for employees to solve more complex tasks.

The basic principle of "one person - one task" disappears. People begin to work in multitasking mode, mastering new professions, forming a new personal competency profile. All of the above changes the approach to assessing human capital in general and approaches to its development.

\section{Results}

Changes in the structure of labor entail a change in approaches to the formation of the structure of human capital. This is no longer a professional profile of a person, development "deep" of the profession, but the formation of a system of competencies that can affect more than one professional sphere.

A person's competency profile should include a number of cognitive skills (critical thinking, decision making under conditions of uncertainty, etc.), social and behavioral skills (the ability to build communication relationships, interpersonal and intercultural interaction, tolerance, etc.).

A person's value in the value chain shifts from performing a specific action to the ability to correctly set a task, correctly interpret the information received, and make a competent decision if the situation turned out to be freelance. These requirements are characteristic of almost all professions in the era of digitalization and acceleration of all processes.

At the same time, at the regional level, employers do not always understand what competencies they need from an employee. When selecting personnel, recruiters often use methods from the Internet about completing a test task, passing psychological tests, etc., which cannot fully evaluate a candidate for a particular position. The authors conducted a survey of employers representing small and medium-sized businesses in four regions of the Central Federal District, which showed that the main claim to the education system on the part of business is inadequate staff training. At the same time, business representatives were 
unable to clearly formulate their position in relation to the required competencies of graduates.

Thus, with a formal balance of employment, Russia experiences an imbalance of competencies.

The reason is the lack of a critical mass of demand for knowledge. The Russian economy is fundamentally a raw material structure that needs the use of resources, not intelligence. This structure of the economy, especially in the regional context, makes the profession of seller, driver, security guard the most popular.

In addition, the culture of startups and investments in them is poorly developed in Russia. Despite the fact that in 2018 the passport of the national project "Small and Medium Enterprises and the Support of Individual Entrepreneurship Initiatives" was approved, most of the respondents would like to organize their own business in the service sector (cafe, beauty salon, fitness center, tire fitting, etc. n.), which does not increase the demand for knowledge.

New jobs in the regions, if they are created, in the majority do not require highly educated personnel. The exception is large high-tech companies that need professional personnel and try to attract them with a system of social guarantees, bonuses, etc. A survey of the leaders of such companies showed that they expect from the education system a "package service" - a ready-made specialist with the required set of competencies. In addition, in most regions of the Russian Federation, the state continues to be the main employer, as most jobs in depressed regions are in the public sector. In turn, the public sector in these regions does not seek to effectively use intellectual resources, using the formal criterion of "higher education" when hiring an employee.

The instability of the current global situation is causing changes that in the near future will affect the change in the entire structure of the global economy. So, for example, the coronavirus epidemic necessitated the transfer of some students from China who, for several reasons, could not return to Russia, to the distance learning format. In addition, there is increasing demand for drones that can deliver goods. According to experts, the coronavirus epidemic served as a trigger to accelerate the digitalization of the global economy, which will end by 2027 instead of the previously predicted 2035 .

Consequently, the requirements for the professions of the near future will be changed. In these conditions, employers cannot predict which specialists and with what set of competencies they will need in the near future.

The role of the education system (at all educational levels and in all regions) currently consists in assessing business development opportunities and predicting what kind of personnel will be needed for the digital economy and changing curricula as soon as possible. To a greater extent, this proposal affects the system of open source software and higher education, which should respond to changes in the external environment.

It is possible to organize student training together with potential employers not only in the format of organizing basic departments, but also in the format of direct participation of business representatives in student training. These can be business-commissioned projects that groups of students begin to develop at the beginning of training and complete with a finished project at the end of the educational institution. In this case, the direct participation of the employer in the training process is ensured, as well as the possibility of a "quick response" of the educational organization to changing business needs by adjusting the curriculum throughout the training period. In other words, training should be more flexible both from the position of the content part, and from the position of the organizational part. This requires changes in the routine processes of educational organizations (for example, the abolition of the provision that the curriculum is unchanged throughout the student's training period), as well as closer interaction with regional business. 
On the part of employers, it is necessary to "see" the education system from a different perspective: as a partner, as an opportunity to gain a competitive advantage in the market by training personnel for their own needs by "getting ahead" of the market. It is this approach that will allow raising the motivation bar for both business and educational organizations. The "Spatial Development Strategy of the Russian Federation" defines the priority areas of production for each region. The first step can be taken by both business and educational organizations, guided by these areas, taking into account the rapidly changing market. Such a practice-oriented approach will allow for the complementarity of business and education and may be a stimulating factor in the development of the regional economy.

\section{Conclusions}

Given the uncertainty of the digital environment and the rapid development of technologies for the development of the country as a whole and regions in particular, it is necessary to ensure the dynamics and quality of human capital development. In countries with high per capita GDP and innovative economies, the proportion of highly skilled workers is the highest in the world, from $22 \%$ to $45 \%$, with an average of $15 \%$ worldwide. However, personnel that meet the requirements of the modern economy will not appear on their own. The educational system should in these conditions take a proactive and prognostic position.

The economy of the 21 st century is rapidly generating new demands for the quality of human capital. In conditions of uncertainty, a person should have a wide range of competencies, allowing him to quickly adapt to changes in the external environment. One of the factors restraining regional development in Russia is the low interregional and intraregional mobility of the population. In this regard, an important task on the part of the state for the development of human capital in the regions is to provide conditions for increasing the mobility of citizens for the purpose of their development and employment, as well as changing the structure of the economy, transferring it to technological footing and increasing the demand for innovation. The education system, in turn, should be transformed towards a predictive model and provide advanced training for people. A business should also evaluate its position in prospects, not focusing only on today. And, accordingly, form a request for personnel of the future.

In general, "attraction points" must be formed within the country that meet the specific requirements of people for the realization of their competencies and ambitions. And it does not have to be metropolitan regions. The task of regional authorities is to ensure the dynamics of territorial development, changing the structure of the economy to meet the needs of a rapidly changing external environment, which together will create a favorable environment for the development of human capital and, accordingly, an increase in the demand for knowledge from the economy.

The main factor that can change the process of formation and effective use of human capital is the desire of the state, business and the training system to work together. Only a comprehensive solution to the problem of the formation and use of human capital can become the key to the effective development of the territory.

The study was carried out with the financial support of the Russian Federal Property Fund in the framework of the scientific project No. 19-29-07125 "Modeling scenarios for the development of human capital in Russia and the development of methodological tools for assessing its impact on economic growth, social well-being and development of Russian society in the context of digitalization of the economy and increasing national competitiveness." 


\section{References}

1. Petty S.W. Verbum Sapienti. Reprinted in the Economic Writings of Sir William Petty. 1899 (1691). Vol. 1. Cambridge: Cambridge University Press

2. Mankiw N.G., Romer D., Weil D. A contribution to the empirics of economic growth, Quarterly Journal of Economics 107, 2, 407-437 (1992)

3. Benhabib J., Spiegel M. The role of human capital in economic development. Evidence from aggregate cross-country data, Journal of Mone tary Economics 34, 143-173 (1994)

4. Growth scenarios of the Russian economy, taking into account the contribution of human capital [Text]: dokl. to Apr 20 Int. scientific conf. on the problems of economic and social development, Moscow, April 9-12. 2019 / N.V. Akindinova, E.G. Yasin, D.A. Avdeeva and others; Nat researched University "Higher School of Economics" (M.: Publ. House of the Higher School of Economics, 2019)

5. World Bank Group, 2019. Changing the nature of labor. World Development Report. https://www.vsemirnyjbank.org/ru/publication/wdr2019

6. Carina Hirsch Schooling, Production Structure and Growth: An Empirical Analysis on Italian Regions (Cagliari: Università di Cagliari, 2007)

7. Golenkov V.A., Stepanov Yu.S., Sadkov V.G., Mashegov P.N. The strategy of innovative development of Russia and the role of university complexes in the modernization of education (M.: Mechanical Engineering-1, 2003)

8. Alan B. Krueger \& Mikael Lindahl, 2001. Education for Growth: Why and for Whom?," Journal of Economic Literature, American Economic Association 39(4), 1101-1136 (2001)

9. Valerio Crispolti \& Daniela Marconi, "Technology transfer and economic growth in developing countries: an econometric analysis," Temi di discussione (Economic working papers) 564, Bank of Italy, Economic Research and International Relations Area (2005)

10. Vlasyuk L.I., Stroyev P.V. Methodology for determining the level of development of human capital and its differentiation in the regions of Russia, Economics of regions 4, 86-95 (2017)

11. Problems of public administration efficiency. The human capital of territories: problems of formation and use (Vologda: Institute of Socio-Economic Development of Territories of the Russian Academy of Sciences, 2013)

12. Regions of Russia. Socio-economic indicators (Stat. Sat / Rosstat. - M., 2018) URL: https://www.gks.ru/free_doc/doc_2018/region/reg-pok18.pdf 